\title{
Computational Approach to Investigation of Crack Behaviour under Vehicular Loading of A Typical Concrete Pavement (A Case Study of Mbagathi Road in Nairobi)
}

\author{
Njiru Joseph Mwaura', Siphila Wanjiku Mumenya ${ }^{2}$ \\ ${ }^{1}$ MSC Student, Civil and Construction Engineering, Nairobi University, P.O Box 30197-00100, Nairobi, KENYA \\ (njimwa@gmail.com) \\ ${ }^{2}$ Siphila Wanjiku Mumenya, Head, Civil and Construction Department, Nairobi University, P.O Box \\ 30197-00100, Nairobi, KENYA (wsiphila@uonbi.ac.ke)
}

Copyright (C) 2014 (Njiru Joseph Mwaura, Siphila Wanjiku Mumenya). This is an open access article distributed under the Creative Commons Attribution-NonCommercial-NoDerivatives 4.0 International License., which allowing others to download this work and share them with others as long as they credit us, but they can't change them in any way or use them commercially. In accordance of the Creative Commons Attribution License all Copyrights (C) 2014 are reserved for $A B C$ Research Alert and the owner of the intellectual property (Njiru Joseph Mwaura, Siphila Wanjiku Mumenya). All Copyright (C) 2014 are guarded by law and by ABC Research Alert as a guardian.

\section{Abstract}

Nairobi County has nearly $100 \%$ road network as bituminous roads and only $4 \mathrm{~km}$ road network (Mbagathi Road) is concrete road. This road was a pilot project that was implemented by Kenyan Government between the years 2005 and 2007 at a total construction cost of over 400 million Kenya Shillings. The design was done based on South Africa design procedure on a 210 mm thick PJCP pavement. Performance of Plain Jointed Concrete Pavement (PJCP) depends on aggregate interlock, which is the mechanism by which loads are transferred from one slab to the adjacent one. This study attempted to use the information on load transfer mechanics in order to quantify the effect of aggregate properties to crack size as well as the propagation of any cracks formed in service. This research was undertaken in two different ways namely experimental and computer simulation. The experimental approach entailed measuring widths and depths of cracks existing in Mbagathi road, and also involved setting up concrete beams in the laboratory and loading them to failure with predetermined loads and measuring sizes of resulting cracks. On the other hand, the computational approach was verified by experimental results entailed simulating crack widths and depths with recent devised fracture models. Cracks were experimentally noticed to occur due to loading the pavement with vehicular loads bigger than safe load. Cracks generated had crack width equivalent to the measured flexural deflection and for an ideal concrete pavement crack width and crack depth exhibited an exponential relationship. It was found that vehicular loads induce stresses in concrete pavements which exceed permissible tensile stresses, hence a better understanding of the resultant cracks, as well as their propagation. This research will lead to an improvement of the design of concrete pavements in Kenyan environment.

Keywords

Pavement, Cracks, Tensile stresses, aggregate, interlock 


\section{Introduction}

Concrete material is inherently brittle hence susceptible to cracking when stresses exceed (tensile stress of $2.71 \mathrm{~N} / \mathrm{mm}^{2}$ for concrete grade 35[1]. Design of major highly loaded pavements proposes a slab depth of $210 \mathrm{~mm}$ [2]. Failure of concrete structures typically involves a stable growth of large cracking zones leading to fractures before the maximum load achieved. Ordinary reinforced concrete design is not based on fracture mechanics. Even it is known that prevention of brittle failures of concrete structures as a safety criterion, on concrete pavements will improve the economy. Concrete pavement was first constructed in Bellefontaine, Ohio; USA in 1893 [3]. The performance of several sections has and is still being monitored and the information has been used in upgrading design and construction methods. Since then Design of Rigid pavements have been done using Analytical Solutions and then numerical solutions. Later in 1965 Cheung and Zienkiewicz designed a pavement using finite element methods where they analysed slabs on both liquid and solid type foundations. Since then pavements of this nature have been designed in different countries. have not concentrated much on failure of these pavements [4]. This research focuses on a where crack characteristics including initiation, growth and eventual failure of pavement are investigated. This will enhance repair and maintenance at the right times. A computer method will be used to design for crack widths in pavements using available predictive models. In research it is assumed that concrete slabs behave as plates. Chudnovsky in 1986 described 'crack layer model' which considers the crack width not being constant as opposed to crack band model which considers it constant [5].

The major predictive model for fracture in concrete pavements is crack band model, the basic idea of crack band model [6].

- Characterize material behaviour in the fracture process zone in a smeared manner through a strain- softening constitutive relation. In the smeared crack band the crack opening ' $\mathrm{w}$ ' is the product of average strain and band width. Softening damage results due to micro-cracking and cause by fracture strain.

- Impose a fixed width of front of the strain-softening zone representing a material property, to avoid spurious mesh sensitivity to ensure energy dissipation due to fracture per unit length is constant; i.e. equal to fracture energy of material.

Vehicular loading in this research is considered as the main contributor to cracking as to temperature and humidity changes. This is because of their repetitive and adverse exposure Nature, which is closely related to fatigue of the elements.

\section{Behaviour of Concrete Pavements}

The function of a concrete road pavement is to support traffic loading and still maintain its rigidity and withstand deterioration effects over its design life. To achieve this, the pavement must enable the stresses in the subgrade caused by traffic loads to be maintained at a level that the subgrade can sustain without the development of cumulative permanent deformation, and without the development of elastic strains of a magnitude that would cause deterioration within the pavement.

When, under the action of wheel vehicular traffic, a concrete pavement slab is loaded to the point of rapture, the concrete fails in tension as a result of flexure rather than in compression. 
In a concrete pavement subject to flexure, the compressive and tensile stresses developed in the outer surfaces of the pavement are approximately equal. The tensile strength of concrete is much less than compressive strength [7]. When the load or bending moment increases to the point approaching rapture, the tensile stresses on the lower side of the pavement reaches the ultimate tensile strength before the compressive stress on the upper side of the pavement reaches the ultimate compressive strength.

In concrete pavement thickness design, the emphasis is centred on controlling horizontal tensile stresses at the lower surface of the concrete caused by this flexural action. The control of tensile strength is achieved by providing a sufficient thickness which in turn is largely dependent on the flexural strength of the concrete [8].

Fatigue in concrete is a progressive permanent internal structural damage when the concrete is subjected to repetitive stresses. Plain concrete when subjected to repetitive loads may exhibit excessive cracking and may eventually fail after sufficient number of load repetitions, even if the maximum load is less than the static strength of a similar specimen [9].

\section{Steel Area per Slab in Concrete Pavement}

Area of steel required for tie bars in the United States is calculated using sub grade drag theory, which is based on equilibrium of drag force of the concrete slab and maximum force that the tie bar can withstand without yielding [10]. The sub grade drag in this system is expressed as given in equation 2.1 .

$$
A_{s}=\frac{b * h * W * f}{100 S_{s}}
$$

Where bis the width of pavement in $\mathrm{mm}, \mathrm{h}$ is the depth of pavement in $\mathrm{mm}, \mathrm{W}$ is the concrete unit weight (e.g. $2400 \mathrm{~kg} / \mathrm{cm}^{2}$ ), $\mathrm{f}$ is the coefficient of friction (i.e. 1.5), $\mathrm{S}_{\mathrm{s}}$ is allowable working stress in steel (e.g. $1750 \mathrm{~kg} / \mathrm{cm}^{2}$ ) and $\mathrm{A}_{\mathrm{s}}$ is the area of steel required to tie bars in $\mathrm{mm}^{2}$.

\section{Theory behind Cracks Formation, Growth and Control}

Cracks occur in nearly all types of roads due to mechanical and environmental loadings. Cracking causes water penetration, weakening foundation of pavement structure and contributing to increased roughness. Engineering structures are designed to withstand the loads they are expected to be subject to while in service. Material imperfections at time of usage of the material are unavoidable; this leads to cracks formation on concrete surfaces. Due to continuous loading of the structure, the crack propagates and enlarges in the direction of critical stresses formation [11].

Crack initiation is related to stress, while crack growth is related to energy dissipation and high stresses surrounding the crack tip. Development of cracks can be quantified if both stress at which fracture starts $(\sigma)$ and typical fracture energy to grow the crack by a unit area (G) is known. Many composite materials commonly used for pavement construction are quasi-brittle and are subjected to considerable size effects in fracture. Size effect is phenomenon where the strength of a structural system depends on its size [12]. Crack formation can be described using models; the main one being cohesive crack approach. This is implemented in Finite element method a modern method that finds many applications in engineering designs. Cohesive crack modelling was first introduced by Hillerborg [20]. In the model, a crack is induced when the stress in the material reaches its tensile strength. After the crack has 
formed, there exists stresses which still continue to be transferred across the crack through the mechanism of aggregate interlock, but the amount of stress transferred decreases with increase in crack width.

Formation of cracks in concrete is undesirable because it largely contributes to wear and deterioration of the whole structure. Cracking and its subsequent propagation can be controlled by appropriate design methods that consider crack reduction designs, materials selection and proportioning and construction practices. When a concrete pavement is being constructed, timing of joints as they are sawn and their depth is relevant [13].

\section{Failure Criteria}

Above the elastic limits solid bodies respond to loading by undergoing large plastic deformations and for brittle materials fracture occurs soon after elastic limit is exceeded.

Fatigue cracking is caused by load repetition that grows edge stress as found at mid slab where there are maximum moments. Other forms of failure in concrete elements include faulting (vertical displacement of abutting slabs at transverse joints creating a step in the pavement), spalling (breakdown of crack edges) and joint deterioration (loss of original surface texture) [14].

\section{Crack Propagation in Plates}

Griffith is regarded as the father of Fracture Mechanics; He observed experimentally that small imperfections have a much less damaging effect on the material properties than the large imperfections [15]. Griffith suggested an energy balance approach based not only on the potential energy of the external loads and on the stored elastic strain energy, but also on another energy term: the surface energy [15]. Formations of cracks results in induced strain energy which Griffith suggested a relationship given in equation 2 .

$\mathrm{U}_{\text {cracked }}-\mathrm{U}_{\text {uncracked }}=-\frac{2 \pi * \mathrm{a}^{2} * \sigma^{2}}{\mathrm{E}}+\frac{\pi * \mathrm{a}^{2} * \sigma^{2}}{\mathrm{E}}+4 \mathrm{a} \gamma$

(Equation 2)

Where a; is the crack length, and $\gamma$ is the unit weight of material, $\mathrm{E}$ is the young modulus for the material and $\sigma$ the stress in $\mathrm{N} / \mathrm{mm}^{2}$.

There are three types of cracking modes, namely Modes I, II, and III. Where Mode I is the tearing of a crack from tensile stresses, Mode II is the sliding of a crack due to in plane shear stresses and Mode III is the tearing of a crack due to out-of plane shearing [15]. 

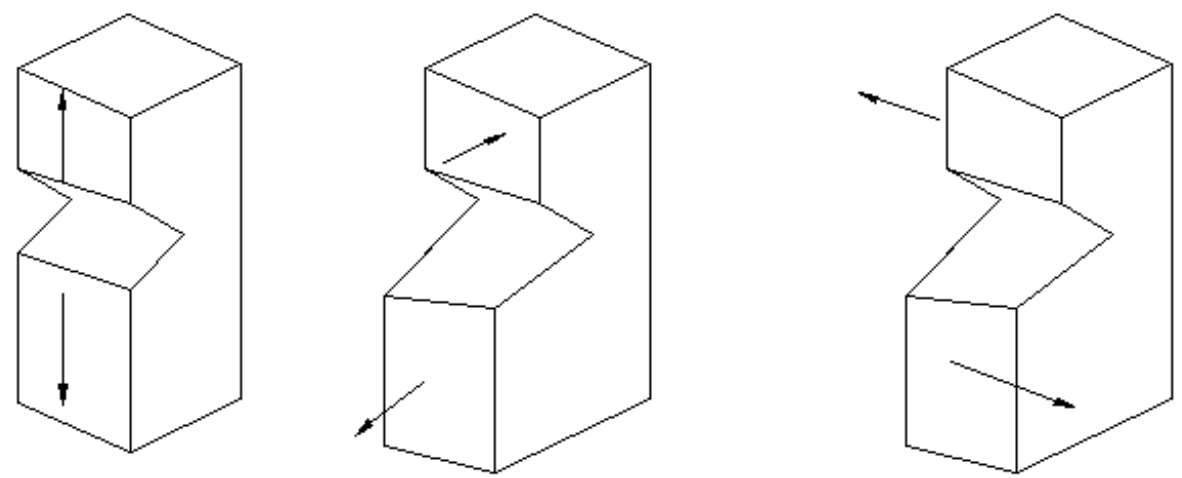

Mode I

Mode II

Mode III

Fig 1: Modes of cracking

\section{Fracture Mechanisms}

\section{Linear elastic fracture mechanism}

It assumes all fracture process happens at the crack tip and the entire volume of the body remains elastic. The stress field which is made up of perturbation of trajectories of maximum principal stress, at the crack tip is singular (stress components are the same regardless of loading and shape of body, with all the non-zero stress components approaching infinity as the radial distance " $r$ " from crack tip tends to zero.

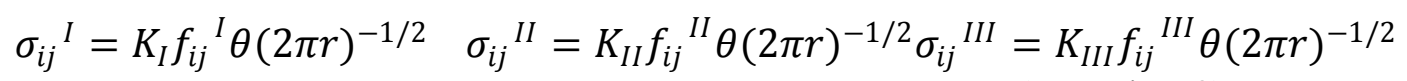

(Equation 3)

Where subscripts I, II, III refers to modes, and $\theta$ is planar angle and $\mathrm{K}_{\mathrm{I}}, \mathrm{K}_{\mathrm{II}}, \mathrm{K}_{\mathrm{III}}$ are stress intensity factors [15].

\section{Non- Linear fracture models with softening zones for non-ductile materials}

Is a mechanism where fracture zone is large and occupies nearly the entire non-linear zone [10]. The fracture process zone is the zone where material undergoes strain-softening i.e. stress normal to the crack plane decreases with increase in strain, and non-linear fracture with softening zone.

\section{Softening stress- strain relations}

The concrete cracks are not straight, but tortuous implying fracture zone can be described using stress- strain relations with strain softening. This method is good for computer programming because there is no separation of nodes of two adjacent elements. Fracture process zone are zones in which material undergoes strain softening. Structurally softening strains are modelled using stress displacement law; since it enables understand internal cracking well [16]. Fracture is handled by adjustment of incremental stiffness of finite elements.

\section{Two dimension fracture matrix from crack band theory}

The crack band theory states that heterogeneous aggregate material exhibits a gradual strain softening due to micro cracking and fracture is modelled as a blunt smeared crack band, which is justified by the random nature of micro structure. Recent method explaining softening is 
caused by fracturing strain ; $\mathrm{e}^{\mathrm{f}}$ which is superimposed on the elastic strain. The two dimensional matrix is given as an output of strains;

Fracture energy is the energy consumed in the formation and opening of micro-cracks per unit area plane. Compliance relationship relates strains and stresses as fracture energy opens the crack [4].

$\left\{\begin{array}{l}\epsilon_{11} \\ \epsilon_{22} \\ \gamma_{12}\end{array}\right\}=\left\{\begin{array}{ccc}C_{1111} & C_{1122} & 0 \\ C_{2211} & C_{2222} & 0 \\ 0 & 0 & C_{1212} / \beta\end{array}\right\}\left\{\begin{array}{l}\delta_{11} \\ \delta_{22} \\ \delta_{12}\end{array}\right\}+\left\{\begin{array}{c}0 \\ \epsilon \\ 0\end{array}\right\}$

Where $\gamma=2 \epsilon_{12}, C_{1111}=C_{2211}=C_{2222}=C_{2212}$ are elastic compliances and $\beta$ varies from 0 to 1

and fracture energy is obtained as $G_{f}=w_{c} \int_{0}^{\infty} \delta_{22} d \epsilon^{f}$

(Equation 5)

where $d \epsilon^{f}$ is the change in elastic strain.

The research will utilize the above equations by formulation of compliance matrices for partially or fully cracked concrete which will be used to find strains induced by principal stress and get extensions of cracks as they grow as also evaluating sizes of cracks.

Though research to modern fracture mechanics is being done, the atomic simulation method where inter atomic bond is ruptured to allow crack propagation and using continuum solution for a cracked body under uniform tension, stresses and displacements are calculated.

\section{Cohesive Zone Model}

The cohesive zone model provides a computationally efficient way to simulate damage occurring in a process zone located ahead of a crack tip. This approach involves non-linear constitutive laws described by the displacement jump and traction along the interfaces. It provides a phenomenological model to simulate fracture behaviour such as crack nucleation, initiation and propagation. Cohesive zone is the region between the material crack tip and the cohesive zone tip where complicated fracture behaviours, including inelasticity occur. The cohesive surfaces are joined together by a cohesive traction, which depends upon the displacement jump across crack faces. As the displacement jump increases due to an increase in external force or compliance in a structure, the traction first increases, then reaches a maximum, and finally decays monolithically to zero. The major cohesive parameters include material strength, critical displacement and cohesive fracture energy.

Cohesive model formulation can be described as shown below:

cohesive energy is obtained as $G_{f}=w_{c} \int_{0}^{\infty} t d \delta \quad$ (Equation 6)

Where $\mathrm{t}$ is the traction and $\delta$ is the normal displacement.

Fracture process zone is given by $\frac{\pi}{8} * \frac{E}{1-\vartheta^{2}} * \frac{G_{c}}{\sigma_{\text {ave }}^{2}} \quad$ (Equation 7)

Where $G_{c}$ is the cohesive energy, $\sigma$ is measure of material strength in the average sense, $\mathrm{E}$ is the young modulus and $\vartheta$ is the Poisson ration for material [17]. 


\section{Numerical Modelling}

The load spectrum tabulates and plots vehicular loads in a frequency curve. Vehicular loads frequencies, cumulative frequencies, mean and standard deviations are calculated, sorting out of critical loads for deflections and crack parameters calculations is done. Plates deform and crack after experiencing large deformations. Euler- Bernoulli beam theory is used to solve deflections at various locations of concrete slabs. Explicit methods are used in numerical modelling of concrete structures. Numerical integration method, consider the solution of the linear dynamic equilibrium equation written in the following form:

$M \ddot{u}+C \dot{u}+K u=F$

(Equation 8)

Where $\mathrm{M}$ is the mass matrix, $\mathrm{C}$ is damping matrix, $\mathrm{K}$ is stiffness matrix and $\ddot{u}, \dot{u}$ and $u$ are acceleration, velocity and displacement [19].

\section{Theoretical and Laboratory Comparison}

\section{Theoretical and Laboratory Testing}

The beam considered had geometric properties has $1000 \mathrm{~mm}$ long, $200 \mathrm{~mm}$ wide and $215 \mathrm{~mm}$ depth. Theoretical determinations considered the beam at elastic conditions utilising theories of beam deflection, while the laboratory methods i.e. flexural testing of beams, yielded deflections at both elastic and plastic state of the beam. In this research, the comparison done was for elastic state of the beam. Deflection load curves were drawn and the resultant equations were compared as illustrated below.

\section{Theoretical and Laboratory Deflections and comparative graph}

The two approaches used had the following data for loads and resultant deflections.

Table 1: Theoretical and laboratory deflections at various loads

\begin{tabular}{|c|c|c|c|}
\hline $\mathbf{P}(\mathbf{k N})$ & $\mathbf{P}(\mathbf{N})$ & $\begin{array}{l}\text { Theoretical Deflection } \\
(\mathrm{mm})\end{array}$ & Laboratory Deflections (mm) \\
\hline 0 & 0 & 0 & 0 \\
\hline 0.5 & 500 & 0.0022 & 0.05 \\
\hline 1.5 & 1500 & 0.0065 & 0.1 \\
\hline 2.5 & 2500 & 0.011 & 0.15 \\
\hline 3 & 3000 & 0.013 & 0.2 \\
\hline 3.4 & 3400 & 0.015 & 0.35 \\
\hline 3 & 3000 & 0.013 & \multirow{3}{*}{ Beyond Elastic poin } \\
\hline 2.5 & 2500 & 0.011 & \\
\hline 2 & 2000 & 0.009 & \\
\hline
\end{tabular}




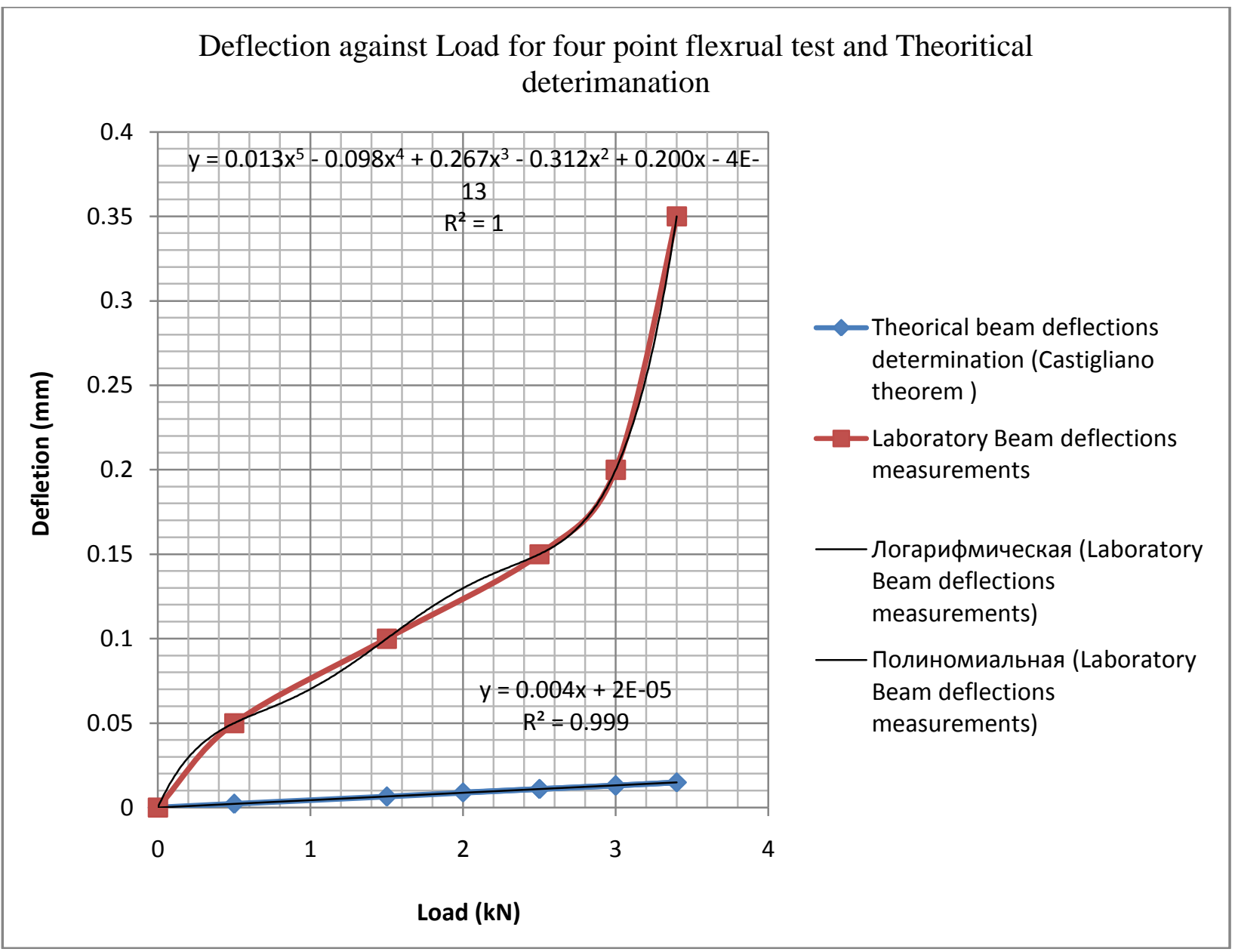

Fig. 2: Comparison of theoretical and laboratory deflections

\section{Discussion}

Laboratory and theoretical deflections model was developed, it was deduced that a factor i.e. $\mathrm{K}_{1}$ related the two data sets.

$\mathrm{D}_{\mathrm{L}}=\mathrm{K}_{1} * \mathrm{D}_{\mathrm{T}}$; where $\mathrm{D}_{\mathrm{L}}$ denotes laboratory deflection, $\mathrm{D}_{\mathrm{T}}$ denotes theoretical deflection and $\mathrm{K}_{1}$ is relationship factor dependent on the force.

$\mathrm{K}_{1}$ was determined by dividing the polynomial equation developed from laboratory deflections and loads by linear equation developed from theoretical deflections and loads and a resultant equation was quadratic equation. $\mathrm{K}_{1}$ was stated as:

$\mathrm{K}_{1}=3 x^{4}-22.455 x^{3}+60.68 x^{2}-70.9 x+45.64 \quad$ (Equation 9)

Where $\mathrm{x}$ is the force in $\mathrm{kN}$

The values for $\mathrm{K}_{1}$ were therefore developed for a number of forces as shown below: 
Table 2: Relationship factor $\mathrm{K}_{1}$ for different loading

\begin{tabular}{|c|c|}
\hline $\mathbf{P}(\mathbf{k N})$ & $\mathbf{K}_{\mathbf{1}}$ \\
\hline 0 & - \\
\hline 0.5 & 22.73 \\
\hline 1.5 & 15.21 \\
\hline 2.5 & 13.96 \\
\hline 3 & 15.77 \\
\hline 3.4 & 24.37 \\
\hline
\end{tabular}

Ideally the factor would be a constant for all forces. The difference would be attributed by human errors on reading the measurement equipment, equipment calibrations or concrete quality and properties during testing.

\section{Field Measurements and Model Comparison}

The model yielded a crack width of $0.137 \mathrm{~mm}$ and a crack depth of $61.9 \mathrm{~mm}$, while the measured crack width and depth in the field ranged between $0.4-0.7 \mathrm{~mm}$ and $86-149 \mathrm{~mm}$ respectively. Laboratory deflections and theoretical deflections ranged between 0 to 0.35 and $0-0.015$.

\section{Discussion}

Laboratory deflections compared with model crack width, there was a direct relationship between deflection value at failure and model crack width.

$\Delta_{F}=C W$

In conclusion, the maximum deflection subjected to a beam to failure, i.e. cracking, influenced the amount of cracks formed, their sizes and the extent of opening.

\section{Conclusion}

a) Crack width and crack depth exhibited an exponential relationship in the S-math studio model; with the biggest crack having a maximum width of $0.2 \mathrm{~mm}$ and a depth of $62 \mathrm{~mm}$. Experimentally they exhibited a degree five relationship with the biggest crack having a maximum width of $0.9 \mathrm{~mm}$ and a depth of $130 \mathrm{~mm}$. Theoretically it was a linear relationship was noted.

S- Math studio model was generated using predictive models based on vehicular loading; the difference is because there are other factors affecting the pavement and needed to be included in the models.

b) Both crack width and crack depth reduce with increased concrete rigidity. Rigidity has direct relationship with strength. Highly rigid pavements are more compact, and less susceptible to cracking.

From the mechanical modelling of the pavement shown in the figure below

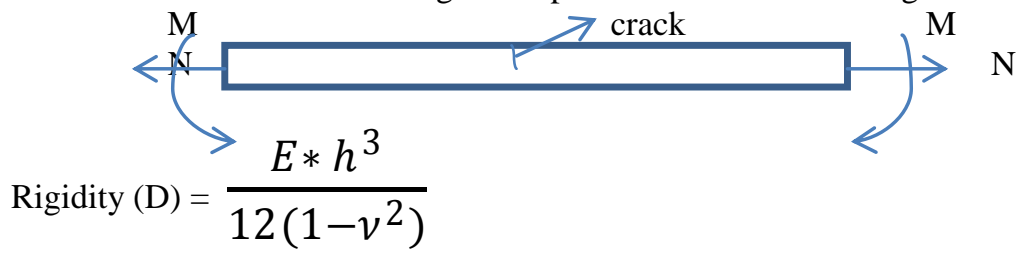

Where $\mathrm{E}$ is the Young Modulus of Concrete dependent on force applied in concrete $\left(\mathrm{N} / \mathrm{mm}^{2}\right), \mathrm{h}$ is the thickness of pavement $(\mathrm{mm})$, and $v$ is the poison's ration of concrete $\mathrm{E}=\frac{F * l}{A * \Delta l}$ where $\mathrm{F}$ is the vehicular loading $(\mathrm{N}), 1$ is the length of pavement slab $(\mathrm{mm})$, A is the wheel load contact area $\left(\mathrm{mm}^{2}\right)$ and $\Delta l$ is the elongation (mm). 
$\mathrm{C}_{\mathrm{mm}}=\frac{2 * l}{D}$ where $\mathrm{C}_{\mathrm{mm}}$ is the compliance of pavement slab strip used to calculate slab crack width $\quad \mathrm{C}_{\mathrm{mm}}=\mathrm{a} / \mathrm{h} \quad$ where $\mathrm{a}$ is the crack width

Compliance is directly proportional to crack width and depth but inversely proportional to rigidity.

c) Heavily loaded pavements would experience more tear and wear due to increased tensile and compressive strength to the pavement.

On observation loaded trucks of up-to $450 \mathrm{kN}$ where noticed using Mbagathi road; experimentally the safe load for Mbagathi road was $430.4 \mathrm{kN}$ hence the reason for cracks formation. The traffic load should be monitored against the safe load presented in this report.

Maximum safe vehicular load for Mbagathi road determined as $430.4 \mathrm{kN}$

d) Transverse cracks

Major cracks developed are either longitudinal cracks which are parallel to the longer dimension of the beam and transverse cracks which are perpendicular to the longitudinal cracks. Transverse cracks were the most critical cracks since they were easily noticed, wide and deep.

e) Cracks width and Beams deflection.

Cracks generated in a pavement due to the fatigue from repetitive loads beyond safe load. Experimentally, there was a linear relationship developed between crack widths determined from the model and deflections recorded during flexural testing of beams. The amount of deflection induced by heavy vehicular loads in a concrete pavement beyond the elastic limit i.e. at elastic-plastic point cracks induces cracks with a width approximately equivalent to the resultant deflection. Maximum flexural force of $3.4 \mathrm{kN}$ yielded a deflection of $3.5 \mathrm{~mm}$. Generally, a maximum deflection of $0.7 \mathrm{~mm}$ was recorded after the beams were loaded beyond failure.

\section{Acknowledgement}

The research leading to these results has received support from School of Engineering, University of Nairobi; Department of Materials Testing (Kenya) and Department of Materials; Norken International Ltd. The author(s) wish to gratefully acknowledge the contribution to their work made by these bodies.

\section{References}

1. Dura, C., Durability Design of Concrete Pavements, Project BE95-1347/R14B, 2000.

2. Manual, M10, Concrete Pavement Design and Construction, Department of Transport, Pretoria, 1995.

3. Yang, H. H., Pavement Analysis and Design Second edition, Prentice Hall Pub , 2003

4. Kare, H., Introduction to Fracture Mechanics, McGraw-Hill Inc. US, 1984

5. Zdenek, P. B., Fracture Mechanics of Concrete Structures, Elsevier Applied Science, London and New York, 1992.

6. Zdenek, P. B., Crack Band Theory for Fracture of Concrete, Northwestern University, 1983. 
7. Norbert J. D., Concrete Pavement Design, Construction and Performance Second Taylor and Francis, 2008.

8. Guo H, J. A. Sherwood, and M.B. Synder," Component Dowel Bar Model for Load Transfer Systems in PCC Pavements," Journal of Transportation Engineering, , pp.287-297, May/June 1995.

9. Miner, M., Cumulative Damage in Fatigue. American Society of Mechanical Journal of Applied Mechanics, 12 (3), 1945.

10. Alex, G., A Mechanistic-Empirical Tie Bar Design Approach for Concrete Pavements, Applied Research Associates, 2009.

11. BS 1881: Part 203, Recommendations for Measurement of the Velocity of Ultrasonic Pulses in Concrete, London, 1986.

12. Tada, H., P.C. Paris and G.R. Irwin., The Stress Analysis of Cracks Handbook. ASME Press, New York, 2008.

13. Bazant, Z.P., and Pfeiffer, P.A.,"Determination of Fracture Energy Properties from Size Effect and Brittleness Number," ACI Mater. J.,V.84, No.6, pp.468-480, 1987.

14. Farmington, H. M., , Control of cracking in concrete, American concrete institute, 1990.

15. Shah S.P., McGarry F.J., Griffith Fracture Criterion and Concrete, Journal of the Engineering Mechanics Division. ASCE Vol.97. No.EM6, Proc. Paper 8597, pp.1663-1676, Dec. 1971.

16. Rice, J. R., A Path Independent Integral and the Approximate Analysis of Strain Concentration by Notches and Cracks. Transactions of ASME, Journal of applied 35: 379-386, 1968.

17. Seong H. S., Paulino, G.H., and Buttlar, W.G, Simulation of crack propagation in concrete using intrinsic cohesive zone model, Transportation Research Board, Washington D.C, 2007.

18. Sansalone M. J., Lin J. W. B Street, Determining the Depth of Surface Openings Cracks Using Impact Generated Stress Waves and Time of Flight Technique," ACI Materials Journal. V.95.No.2., 1998.

19. Shin, S.W., Popovics, J. S., Crack Depth Determination in Concrete Using Energy Transmission of Surface Waves, ACI Materials. Vol.105.No.5, 2008.

20. Arne Hillerborg., Application of Fracture Mechanics to Concrete, Summary of a series of lecture notes, 1988. 